\title{
Volume-Time Curve: An Alternative for Endotracheal Tube Cuff Management
}

\author{
Douglas Willian Bolzan PT, Walter Jose Gomes MD MSc PhD, \\ Sônia Maria Faresin MD MSc PhD, Antônio Carlos de Camargo Carvalho MD MSc PhD, \\ Ângelo Amato Vincenzo De Paola MD MSc PhD, and Solange Guizilini PT MSc PhD
}

\begin{abstract}
BACKGROUND: Despite numerous studies on endotracheal tube cuff pressure (CP) management, the literature has yet to establish a technique capable of adequately filling the cuff with an appropriate volume of air while generating low $\mathrm{CP}$ in a less subjective way. The purpose of this prospective study was to evaluate and compare the CP levels and air volume required to fill the endotracheal tubes cuff using 2 different techniques (volume-time curve versus minimal occlusive volume) in the immediate postoperative period after coronary artery bypass grafting. METHODS: A total of 267 subjects were analyzed. After the surgery, the lungs were ventilated using pressure controlled continuous mandatory ventilation, and the same ventilatory parameters were adjusted. Upon arrival in the ICU, the cuff was completely deflated and re-inflated, and at this point the volume of air to fill the cuff was adjusted using one of 2 randomly selected techniques: volume-time curve and minimal occlusive volume. We measured the volume of air injected into the cuff, the $\mathbf{C P}$, and the expired tidal volume of the mechanical ventilation after the application of each technique. RESULTS: The volume-time curve technique demonstrated a significantly lower $\mathrm{CP}$ and a lower volume of air injected into the cuff, compared to the minimal occlusive volume technique $(P<.001)$. No significant difference was observed in the expired tidal volume between the 2 techniques $(P=.052)$. However, when the subjects were submitted to the minimal occlusive volume technique, $17 \%$ $(n=47)$ experienced air leakage as observed by the volume-time graph. CONCLUSIONS: The volume-time curve technique was associated with a lower $\mathrm{CP}$ and a lower volume of air injected into the cuff, when compared to the minimal occlusive volume technique in the immediate postoperative period after coronary artery bypass grafting. Therefore, the volume-time curve may be a more reliable alternative for endotracheal tube cuff management. Key words: endotracheal tube cuff pressure; air leakage; volume-time curve; minimal occlusive volume technique; cuff pressure management; coronary artery bypass surgery. [Respir Care 2012;57(12):2039-2044. (C) 2012 Daedalus Enterprises]
\end{abstract}

\section{Introduction}

In patients undergoing mechanical ventilation (MV), the endotracheal tube (ETT) cuff should be kept inflated to

\footnotetext{
The authors are affiliated with the Cardiology Division, Escola Paulista de Medicina, Federal University of São Paulo, São Paulo, Brazil, with the exception of Dr Faresin, who is affiliated with the Pneumology Division, Escola Paulista de Medicina, Federal University of São Paulo, São Paulo, Brazil. Dr Gomes, is also affiliated with the Cardiovascular Surgery Discipline, Pirajussara and São Paulo Hospitals, Dr Guizilini is also affiliated with the Department of Human Movement Sciences, Physical Therapy School, Federal University of São Paulo, Santos, São Paulo, Brazil.
}

prevent air leakage and the aspiration of oropharyngeal contents. However, if the cuff is overinflated, even slightly, it can exert too much pressure against the trachea and obstruct mucosal blood flow, leading to ischemic complications and damage to the tracheal wall. On the other

\footnotetext{
The authors have disclosed no conflicts of interest.

Correspondence: Walter Jose Gomes MD MSc PhD, Cardiology Division, Escola Paulista de Medicina, Federal University of São Paulo, Rua Napoleão de Barros, 715 São Paulo, São Paulo 04024-002 Brazil. E-mail: wjgomes.dcir@epm.br.
}

DOI: $10.4187 /$ respcare.01812 
hand, low pressures can predispose to the aspiration of subglottic secretions, resulting in nosocomial pneumonia and poor ventilation secondary to gas leakage. In patients undergoing $\mathrm{MV}$, the suggested ETT cuff pressure $(\mathrm{CP})$ varies from 20 to $30 \mathrm{~cm} \mathrm{H}_{2} \mathrm{O} .{ }^{1,2}$

There is a consensus in the literature that the cuff must be inflated carefully until the air leak stops. ${ }^{1}$ Some studies argue that the best way to properly adjust the ETT CP is via the minimal occlusive volume technique, also known as the seal pressure technique. ${ }^{3-5}$ However, with this technique it is not easy to precisely determine when to stop inflating, which means that high or insufficient $\mathrm{CP}$ can seal the airway. ${ }^{6,7}$

Despite numerous studies ${ }^{3-10}$ documenting the importance of the assessment and the maintenance of the CP within an appropriate range, an easy application technique has yet to be described that is capable of calibrating the volume of air to be injected into the cuff in a less subjective form while maintaining a low CP.

The volume-time curve has been previously used to select the appropriate uncuffed ETT diameter in children on MV, due to its capacity to reveal air leakage. ${ }^{11} \mathrm{We}$ hypothesized that the volume-time curve would be able to promote a more adequate volume of air to fill the cuff, when compared to the minimal occlusive volume technique.

The purpose of this prospective study was to evaluate and compare the behavior of the $\mathrm{CP}$ levels and air volume required to fill the ETT cuff using the 2 techniques (volume-time curve versus minimal occlusive volume), in the immediate postoperative period after coronary artery bypass grafting $(\mathrm{CABG})$.

\section{Methods}

The institutional ethics committee of the Federal University of Sao Paulo approved this study. All subjects were informed and provided written consent prior to their inclusion. A total of 267 subjects hospitalized at the Pirajussara and Sao Paulo Hospitals of the Federal University of Sao Paulo, Sao Paulo, Brazil, who underwent elective CABG from September of 2004 to February of 2009, were prospectively included. Inclusion criteria were age 18 years or older, oral endotracheal intubation, conventional MV, and the absence of respiratory drive. Patients with obesity, chronic respiratory disease, laryngeal disease or anomalies, and a difficult intubation (defined as 2 or more attempts) were excluded from the study.

Lung function indicators, including FVC and $\mathrm{FEV}_{1}$, were evaluated at bedside on the day before the operation, using a portable spirometer (Spirobank G, MIR, Rome, Italy) to exclude chronic respiratory disease, according to the standards of the American Thoracic Society. ${ }^{12}$

\section{QUICK LOOK}

\section{Current knowledge}

During mechanical ventilation the tracheal tube cuff pressure is recommended to be between 20 and $30 \mathrm{~cm} \mathrm{H}_{2} \mathrm{O}$. Excess pressure is associated with tracheal injury, and insufficient pressure is associated with aspiration. The optimal method for cuff management remains unclear.

\section{What this paper contributes to our knowledge}

The volume-time curve technique for managing cuff pressure was associated with a lower cuff pressure and a lower volume of air injected into the cuff, compared to the minimal occlusive volume technique. The volume-time curve may be a more reliable alternative for endotracheal tube cuff management.

\section{Anesthesia and Operative Technique}

Anesthesia was induced in a routine fashion with etomidate and midazolam and maintained with sufentanil and isoflurane. Standard ETTs were used with a high residual volume, a low-pressure cuff, and an inner diameter of $7.5 \mathrm{~mm}$ for female subjects and $8.0 \mathrm{~mm}$ for male subjects. Subjects were ventilated to maintain normocapnia with an $\mathrm{F}_{\mathrm{IO}_{2}}$ between 0.50 and 0.60 , without PEEP.

The operation was performed through a midline sternotomy and using the left internal thoracic artery, complemented with additional saphenous vein grafts. In all cases where the pleural cavity was incidentally opened, a pleural drain was inserted. In all subjects, a mediastinal tubular drain was also left in the subxyphoid region.

\section{Postoperative Management}

After surgery the subjects were transferred to the ICU and ventilated using pressure controlled continuous mandatory ventilation at 14 breaths/min, with an inspiratory time of 1.2 seconds, a PEEP of $5 \mathrm{~cm} \mathrm{H}_{2} \mathrm{O}$, an inspiratory pressure to promote a tidal volume of $8 \mathrm{~mL} / \mathrm{kg}$ of predicted body weight, and an $\mathrm{F}_{\mathrm{IO}_{2}}$ adjusted to maintain the arterial oxygen saturation above $90 \%$. Thirty minutes after ICU arrival and MV initiation, 2 different techniques of cuff insufflation were performed in all subjects (with an interval of $20 \mathrm{~min}$ ), in random order, as generated by a computer software, and the randomization assignments were concealed using opaque, sealed, numbered envelopes until the time of technique application, which proceeded as follows: 


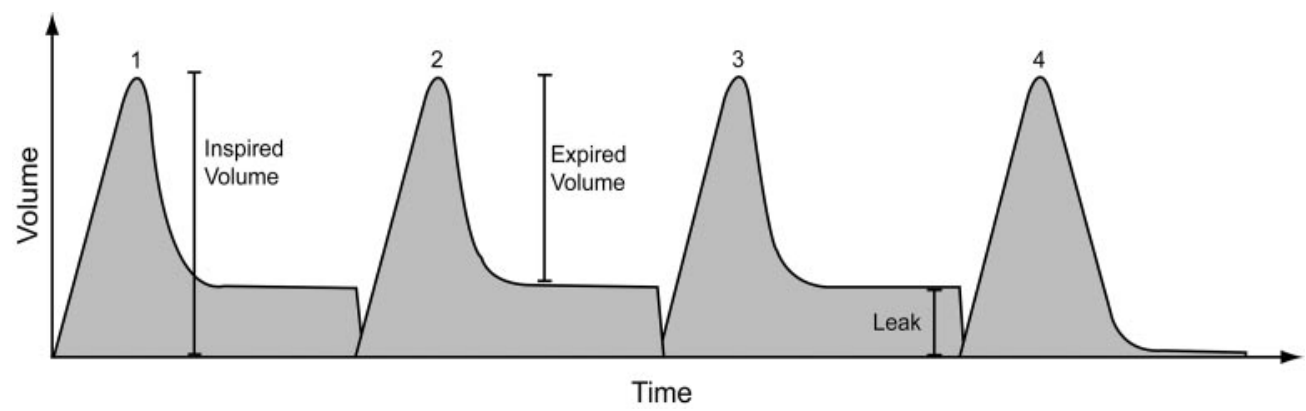

Fig. 1. Volume-time curve. In the first curve, note the inspired volume in the ascendant branch. In the second curve, the descendant branch does not reach the baseline, and the expired volume is smaller than the inspired volume. In the third curve, an air leak can be observed, as represented by a flattening of the curve. The fourth curve represents a normal curve without air leak; note that the inspired and expired volumes are equal, and the descendant branch of the curve returns to the baseline.

- Volume-Time Curve Technique. After complete cuff deflation, a gradual re-inflation was promoted with a $20 \mathrm{~mL}$ syringe, while the examiner analyzed the volume-time curve to properly adjust the necessary air volume to be injected into the cuff. The volume-time curve analysis was performed using a specific device for the evaluation of respiratory mechanics (Ventcare $9505 \mathrm{VSF}$, Takaoka, Sao Paulo, Brazil) and utilizing a pressure transducer interposed between the mechanical ventilator circuit and the ETT. The volume-time curve is able to demonstrate the presence of air leaks. Air leaks result in a decreased expired tidal volume $\left(\mathrm{V}_{\mathrm{T}}\right)$ relative to the inspiratory volume. In the presence of air leakage, the descending branch of the volume-time curve does not reach zero, instead demonstrating a plateau that is then abruptly interrupted by the initiation of the next inspiration (Fig. 1). The time of the flattening of the expiratory branch of the curve was used to determine the air leakage. Inflation was performed until the descending branch of the volumetime curve returned to zero, reversing the flattening observed earlier. The volume of air injected into the cuff to reverse the flattening, the expired $\mathrm{V}_{\mathrm{T}}$ of the mechanical ventilator, and the $\mathrm{CP}$ were each recorded.

- Minimal Occlusive Volume Technique (Seal Pressure). First, a $20 \mathrm{~mL}$ syringe was attached to the pilot balloon, and the cuff was completely deflated. The cuff was then progressively inflated by injecting air until the leak disappeared. During inflation, the examiner kept his ear canal at a distance of $10 \mathrm{~cm}$ from the mouth of the subject to ensure the absence of an air leak. The volume of air injected into the cuff, the expired $\mathrm{V}_{\mathrm{T}}$ of the mechanical ventilator, and the $\mathrm{CP}$ required to seal the airway were assessed in that order. After the completion of the minimal occlusive volume technique, the examiner verified on the volume-time curve the presence or absence of any air leakage.

The $\mathrm{CP}$ was measured using a manometer graduated in cm $\mathrm{H}_{2} \mathrm{O}$ (VBM Medizintechnik, Sulz am Neckar, Ger-

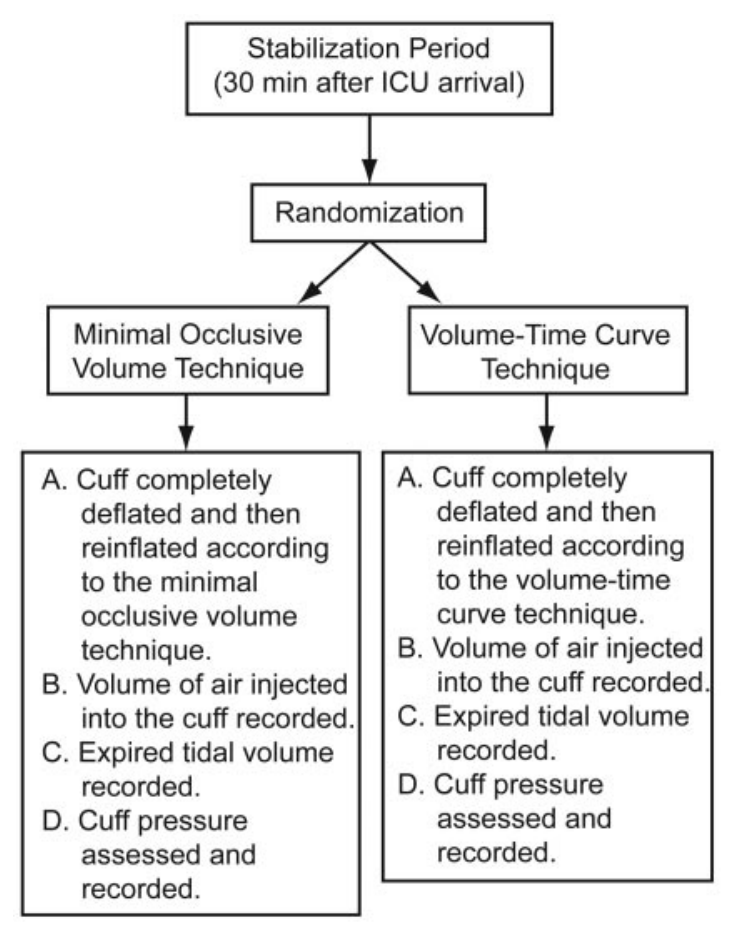

Fig. 2. Study design.

many) that was connected to the inflating channel of the pilot balloon always after expired $\mathrm{V}_{\mathrm{T}}$ evaluation. The study design is shown in Figure 2. Throughout the entire study period, the absence of a respiratory drive was required, and subjects were maintained in the supine position. The head of the bed was kept at an elevation of $30^{\circ}$, and the subject's head and neck were maintained midline with no flexion, extension, or rotation.

\section{Statistical Analysis}

Data are expressed as mean $\pm \mathrm{SD}$. The differences in the air volume needed to fill the cuff and the $\mathrm{CP}$ between the 2 techniques were expressed as percentages. The air 


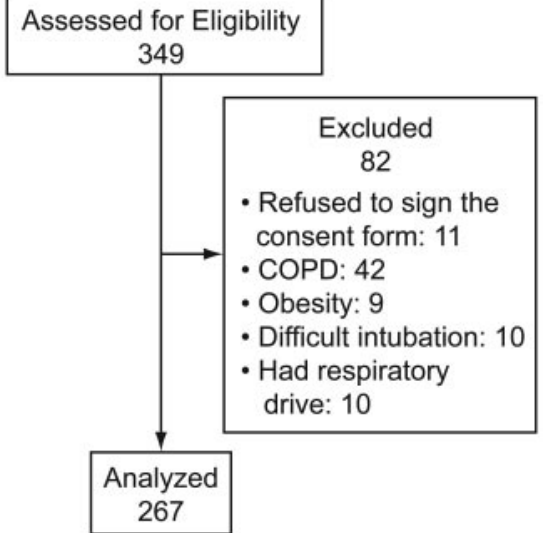

Fig. 3. Participant flow.

Table 1. Perioperative Clinical and Demographic Subject Characteristics $(n=267)$

\begin{tabular}{lc}
\hline \hline Age, $y$ & $65.48 \pm 8.54$ \\
Male/female, no. & $183 / 84$ \\
Body mass index, $\mathrm{kg} / \mathrm{m}^{2}$ & $24.84 \pm 2.22$ \\
$\mathrm{FVC}, \mathrm{L}$ & $3.54 \pm 0.76$ \\
$\mathrm{FVC}, \%$ predicted & $96.93 \pm 11.42$ \\
$\mathrm{FEV}_{1}, \mathrm{~L}$ & $2.78 \pm 0.73$ \\
$\mathrm{FEV}_{1}, \%$ predicted & $97.22 \pm 10.81$ \\
Operation time, min & $305.72 \pm 11.79$
\end{tabular}

\pm Values are mean $\pm S D$

volume injected into the cuff, the $\mathrm{CP}$, and the expired $\mathrm{V}_{\mathrm{T}}$ values were each compared between the 2 techniques, using the unpaired Student $t$ test. Statistical analyses were performed with statistics software (Prism 3.0, (GraphPad Software, San Diego, California). A value of $P<.05$ was considered statistically significant.

\section{Results}

During the study period, 349 patients fulfilled eligibility criteria. From that sample, 267 were actually analyzed (Fig. 3). The preoperative and intraoperative subject characteristics are summarized in Table 1 .

The volume-time curve technique demonstrated significantly lower CPs and volume of air injected into the cuff, compared to the minimal occlusive volume technique $(P<.001)$ (Table 2). No significant difference was observed between the volume-time curve and the minimal occlusive volume technique with respect to the expired $\mathrm{V}_{\mathrm{T}}$ $(491.17 \pm 49.55 \mathrm{~mL}$ vs $482.88 \pm 49.05 \mathrm{~mL}$, respectively, $P=.052)$. However, when the subjects were submitted to the minimal occlusive volume technique, $17 \%(n=47)$ experienced air leakage, as observed by the volume-time
Table 2. Absolute Values and Percent Differences in the Air Volume Used to Fill the Cuff and the Cuff Pressure Between the Volume-Time Curve and the Minimal Occlusive Volume Techniques

\begin{tabular}{|c|c|c|c|}
\hline & $\begin{array}{c}\text { Volume- } \\
\text { Time Curve } \\
\text { Technique } \\
\text { (mean } \pm \text { SD) }\end{array}$ & $\begin{array}{c}\text { Minimal } \\
\text { Occlusive } \\
\text { Volume } \\
\text { Technique } \\
\text { (mean } \pm \mathrm{SD} \text { ) }\end{array}$ & $P$ \\
\hline Air volume to fill the cuff, $\mathrm{mL}$ & $4.21 \pm 0.38$ & $4.59 \pm 0.45$ & $<.001$ \\
\hline Percent difference & & $9.35 \pm 9.52$ & \\
\hline Cuff pressure, $\mathrm{cm} \mathrm{H}_{2} \mathrm{O}$ & $32.76 \pm 3.91$ & $36.78 \pm 4.75$ & $<.001$ \\
\hline Percent difference & & $12.42 \pm 10.61$ & \\
\hline
\end{tabular}

graph. In this subgroup the air volume injected into the cuff was $8 \pm 2.69 \%$ lower in the minimal occlusive volume group, relative to the volume-time group. The $\mathrm{CP}$ was also $7 \pm 2.40 \%$ less in the minimal occlusive volume group.

\section{Discussion}

The volume-time curve technique was associated with a smaller volume of air injected into the cuff and a lower $\mathrm{CP}$, compared to the minimal occlusive volume technique in this group of subjects in the immediate postoperative period after CABG.

To our knowledge, this study is the first to propose the use of graphical monitoring of the volume-time curve as an alternative to promoting ETT cuff inflation. A previous report demonstrated the volume-time curve as a useful tool to show air leakage around the ETT. However, that report only described the ability of the volume-time curve to assist in selecting the diameter of an ETT without a cuff in pediatric patients undergoing MV. ${ }^{11}$ Therefore, a novel aspect of our study was the proposal to use the volumetime graph as an alternative way of promoting adequate cuff inflation.

Several studies have argued that the main function of the ETT cuff is to seal the airway. ${ }^{6-10}$ The CP generated by cuff inflation should be sufficient to prevent air leakage around the cuff, to ensure the correct tidal volume delivery, ${ }^{13}$ to prevent the aspiration of subglottic secretions, and to prevent injury to the tracheal wall. ${ }^{14,15}$ Precise $\mathrm{CP}$ values are not yet known, but suggested $\mathrm{CP}$ values vary from 20 to $30 \mathrm{~cm} \mathrm{H}_{2} \mathrm{O}$.

Depending on anatomical variations of the trachea, these pressures may not be high enough to ensure an adequate seal of the airway. Metha and Myat ${ }^{16}$ suggested that, due to variations in the diameter and shape of the human trachea, a higher or lower pressure to seal the airway might be required, not necessarily equalizing to the tracheal wall pressure. ${ }^{17,18}$ In addition, even fixed pressures within a 
range considered as safe can predispose to the development of tracheal mucosal injuries, most likely due to the relation between tracheal diameter and tube size. ${ }^{3}$

In our study, independent of the technique used (minimal occlusive volume or volume-time curve), we found values of $\mathrm{CP}$ higher than $30 \mathrm{~cm} \mathrm{H}_{2} \mathrm{O}$. We hypothesize that this finding occurred due to anatomical variations of the trachea. Although the volume-time curve resulted in a $\mathrm{CP}$ of approximately $32.76 \mathrm{~cm} \mathrm{H}_{2} \mathrm{O}$, this value was lower than the $\mathrm{CP}$ achieved when the minimal occlusive volume technique was applied. This fact confers to the volume-time curve a clinical advantage in relation to the minimal occlusive volume technique. According to Seegobin and colleagues, ${ }^{19}$ the higher the $\mathrm{CP}$, the greater the reduction in blood flow and tracheal perfusion and the greater the risk of tracheal ischemia occurring; the total obstruction of tracheal blood flow occurs with pressures of approximately $50 \mathrm{~cm} \mathrm{H}_{2} \mathrm{O}$.

Evidence suggests that, when using the minimal occlusive volume technique, it is difficult to precisely determine when to stop inflating the cuff, which can result in higher or lower pressures to promote an adequate airway seal.6,7 The present study supports the aforementioned findings ${ }^{6,7}$; we observed that the use of the minimal occlusive volume technique was associated with high and insufficient $\mathrm{CP}$, resulting in air escape.

The air volume injected into the cuff was $9 \%$ higher with the minimal occlusive volume technique, relative to the volume-time curve. This difference translated into a significant increase of $12 \%$ in the CP in the minimal occlusive volume group. In this study the smaller air volume injected into the cuff was most likely responsible for the smaller CP found when the volume-time curve was applied.

In our study no significant changes were observed in the expired $\mathrm{V}_{\mathrm{T}}$ after cuff inflation with either technique. This fact suggests that both techniques may effectively promote the adequate sealing of the airway. However, when the subjects were submitted to the minimal occlusive volume technique, $17 \%$ demonstrated air leakage, as observed by the volume-time graph. This fact may have possibly contributed to the absence of a significant difference in the expired $\mathrm{V}_{\mathrm{T}}$ values between the groups. Based on our findings, we conclude that the minimal occlusive volume technique may be associated with an insufficient sealing of the airway in some cases and cuff hyperinflation in other cases, which may result in increased risks of air leakage and tracheal wall damage, respectively.

One of our study questions was to determine the best way to identify the exact moment when the air leak stops with the volume-time curve versus the minimal occlusive volume technique. Despite its widespread use and consideration as the most appropriate technique, the minimal occlusive volume technique can still be considered sub- jective, as it depends on the training, skills, and keen sense of the operator. In contrast, during the entire study period the volume-time curve was shown to be a reliable and easily applicable technique. Our study demonstrated the clinical importance of monitoring cuff inflation using the volume-time curve, due to the capacity of this technique to identify in real time the exact air volume needed to fill the cuff to prevent air leakage, simply by observing the curve during cuff inflation. This fact can explain the lower $\mathrm{CP}$ employed in the volume-time curve group. Given that most mechanical ventilators in use today have graphic monitoring, the volume-time curve technique could be easily applied in clinical practice.

Evidence suggests that even experienced professionals were unable to inflate the ETT cuff to generate the least possible CP. Methods such as the palpation of the pilot balloon and the disappearance of an audible air leak are inaccurate ways of assessing an adequate volume to inflate the ETT cuff, and most of the time these methods result in a higher $\mathrm{CP}$ than needed to seal the airway. ${ }^{20} \mathrm{We}$ believe that the use of standardized instruments such as graphic monitoring to inflate the ETT cuff may help to improve the safety of ETT cuff management, decreasing the possibility of injury resulting from ETT cuff over- or underinflation.

\section{Conclusions}

The volume-time curve technique was associated with a lower CP and a reduced volume of air injected into the cuff when compared to the minimal occlusive volume technique in the immediate postoperative period after CABG. Therefore, the volume-time curve may be a more reliable alternative for ETT cuff management.

\section{REFERENCES}

1. Vyas D, Inweregbu K, Pittard A. Measurement of tracheal tube cuff pressure in critical care. Anaesthesia 2002;57(3):275-277.

2. Mahul P, Auboyer C, Jospe R, et al. Prevention of nosocomial pneumonia in intubated patients: respective role of mechanical subglottic secretions drainage and stress ulcer prophylaxis. Intensive Care Med 1992;18(1):20-25.

3. Castilho EC, Braz JR, Catâneo AJ, Martins RH, Gregório EA, Monteiro ER. Effects of tracheal tube cuff limit pressure $\left(25 \mathrm{~cm} \mathrm{H}_{2} \mathrm{O}\right)$ and "seal" pressure on tracheal mucosa of dogs. Rev Bras Anestesiol 2003;53(6):743-755.

4. Fernandez R, Blanch L, Mancebo J, Bonsoms N, Artigas A. Endotracheal tube cuff pressure assessment: pitfalls of finger estimation and need for objective measurement. Crit Care Med 1990;18(12): 1423-1426.

5. Braz JR, Navarro LH, Takata IH, Nascimento Júnior P. Endotracheal tube cuff pressure: need for precise measurement. São Paulo Med J 1999;117(6):243-247.

6. Sole ML, Aragon D, Bennett M, Johnson RL. Continuous measurement of endotracheal tube cuff pressure: how difficult can it be? AACN Adv Crit Care 2008;19(2):235-243. 


\section{Volume-Time Curve: An Alternative for Endotracheal Tube Cuff Management}

7. Blanch PB. Laboratory evaluation of 4 brands of endotracheal tube cuff inflator. Respir Care 2004;49(2):166-173.

8. Farré R, Rotger M, Ferre M, Torres A, Navajas D. Automatic regulation of the cuff pressure in endotracheally-intubated patients. Eur Respir J 2002;20(4):1010-1013.

9. Jain MK, Tripathi CB. Endotracheal tube cuff pressure monitoring during neurosurgery: manual vs automatic method. J Anaesthesiol Clin Pharmacol 2011;27(3):358-361.

10. Al-Metwalli RR, Al-Ghamdi AA, Mowafi HA, Sadek S, Abdulshafi M, Mousa WF. Is sealing cuff pressure, easy, reliable and safe technique for endotracheal tube cuff inflation? A comparative study. Saudi J Anaesth 2011;5(2):185-189.

11. Ramírez JB. Respiratory function monitoring: curves of pressure, volume and flow. An Pediatr (Barc) 2003;59(3):264-277.

12. American Thoracic Society. Standardization of spirometry, 1994 update. Am J Respir Crit Care Med 1995;152(3):1107-1136.

13. Sengupta P, Sessler DI, Maglinger P, Wells S, Vogt A, Durrani J, Wadhwa A. Endotracheal tube cuff pressure in three hospitals, and the volume required to produce an appropriate cuff pressure. BMC Anesthesiol 2004;4(1):8.
14. Jensen PJ, Hommelgaard P, Sondergaard P, Eriksen S. Sore throat after operation: influence of tracheal intubation, intracuff pressure and type of cuff. Br J Anaesth 1982;54(4):453-457.

15. Silva MJ, Aparício J, Mota T, Spratley J, Ribeiro A. Ischemic subglottic damage following a short-time intubation. Eur J Emerg Med 2008;15(6):351-353.

16. Mehta S, Myat HM. The cross-sectional shape and circumference of the human trachea. Ann R Coll Surg Engl 1984;66(5):356-358.

17. McGinnis GE, Shively JG, Patterson RL, Magovern GJ. An engineering analysis of intratracheal tube cuffs. Anesth Analg 1971; 50(4):557-564.

18. Carroll R, Hedden M, Safar P. Intratracheal cuffs: performance characteristics. Anesthesiology 1969;31(3):275-281

19. Seegobin RD, van Hasselt GL. Endotracheal cuff pressure and tracheal mucosal blood flow: endoscopic study of effects of four large volume cuffs. BMJ (Clin Res Ed) 1984;288(6422):965-968.

20. Parwani V, Hoffman RJ, Russell BC, Preblick C, Hahn IH. Practicing paramedics cannot generate or estimate safe endotracheal tube cuff pressure using standard techniques. Prehosp Emerg Care 2007; 11(3):307-311. 